\title{
Comparison of different olive oil extraction systems and the effect of storage conditions on the quality of the virgin olive oil
}

\author{
By S.A. Vekiari ${ }^{a \star}$, P. Papadopoulou ${ }^{a}$ and A. Koutsaftakis ${ }^{b}$ \\ $a^{*}$ Institute of Technology of Agricultural Products 1, S. Venizelou str., Lykovrissi, Athens 14123, Greece \\ Tel.: +30 12845940, Fax: +30 1 2840740, E-mail: itap@otenet.gr \\ ${ }^{b}$ Institute of Subtropical Plants and Olive tree Agrokipio, Souda, Chania, 73100, Crete, Greece \\ Tel.: +30 821 97142, Fax: +30 821 96936, E-mail: aric@cha.forthnet.gr
}

\section{RESUMEN}

Comparación entre diferentes sistemas de extracción de aceite de oliva y efecto de las condiciones de almacenamiento en la calidad del mismo.

Se ha estudiado el efecto de los diferentes métodos de extracción del aceite de oliva en distintos parámetros de calidad del aceite, tales como el índice de peróxido y los coeficientes de extinción $\mathrm{K}_{232}$ y $\mathrm{K}_{270}$. Se ha extraído el aceite de oliva usando el sistema tradicional de Theocharis, sistemas por centrifugación Alfa-Laval y Amenduni y mixto tipos Rapanelli Sinolea y Decanter. El aceite ha sido analizado antes y durante su conservación en botellas de polietileno en ausencia de luz, con luz difusa y con luz solar. El aceite conservado en la oscuridad tuvo el índice de peróxido mas bajo. En general el proceso de oxidación fue lento en la oscuridad y mas rápido en luz difusa y en presencia directa de luz solar.

PALABRAS-CLAVE: Aceite de oliva - Calidad - Sistema centrifugo - Sistema clásico - Sistema mixto.

\section{SUMMARY}

Comparison of different olive oil extraction systems and the effect of storage conditions on the quality of the virgin olive oil.

The effect of different processing systems on the olive oil quality parameters of peroxide value and extinction coefficients $\mathrm{K}_{232}$ and $\mathrm{K}_{270}$ was studied. Olive oil was extracted by the traditional system of Theocharis, the centrifugal systems Alfa-Laval and Amenduni and the mixed type Rapanelli Sinolea and Decanter systems. The oil samples were analyzed initially and during storage in polyethylene bottles in the dark, diffused light and direct sunlight. Samples stored in the dark had significantly lower peroxide value. In general, the process of oxidation was slow in darkness and faster in diffused and direct light.

KEY-WORDS: Extraction systems - Classical system - Centrifugal system - Mixed system - Olive oil quality.

\section{INTRODUCTION}

Olive oil has a special place among the vegetable oils due both to its characteristic rich flavor and its association with healthy eating. It can be considered as the fruit juice of the olive and as such is directly consumable after cold pressing of the olive and separation of the oil by mechanical means. Many factors affect the olive oil quality during and after processing. Of these the most significant are: the oil extraction method and equipment, the storage conditions, the duration of preservation and the packaging materials (Kiritsakis, 1988/ Boskou, 1996).

Olive processing consists of the following stages: milling, mixing, pressure or centrifugation for classic and centrifugal systems respectively, and separation of the oil phase. Olive oil extraction techniques have been developed throughout history, with more and more mechanization being applied in order to reduce manpower and costs. Pressure systems are based on the principle that the olive paste after being pressed under the right conditions, it releases an oily must (olive oil+ vegetation water/liquid phase) and this is separated from the solid phase with the help of the drainage effect of mats and stone fragments. A tendency for classical systems to be replaced by centrifugal systems has appeared during the last twenty years, after many years of investigation. The centrifugal force produced by high-speed rotating machines increases the difference between the specific weight of the immiscible liquid and the solid matter and this is used to extract the oil from the olives. Recently, a return to traditional methods of olive oil extraction has been noticed, with stone mill press equipment being used for the production of so called ecological olive oil (Stavroulakis, 1998). The working stock of olive oil extraction equipment used in Greece is represented by classical, centrifugal and mixed type systems. The operation of mixed systems is based on a combination of selective filtration and centrifugation or pressing.

Storage conditions of virgin olive oil are very important and care must be taken in order to reduce or completely avoid autoxidation, which has a negative effect on the qualitative characteristics of the packaged product. Factors affecting olive oil quality during storage are temperature, exposure to light and contact with oxygen (Kiritsakis, 1984). Light 
is an initiator of reactions that ultimately result in deterioration of the oil. Sensitizers such as chlorophyll may play a role in promoting photooxidation. The type of packaging has a dramatic effect on the shelf life of the oils. Oil that has been carefully processed to maximize palatability may be damaged by improper selection of the storage container. It is desirable to maintain the product quality at an optimum level for the longest time period (Leo, 1983). Papers concerning the behavior of various packaging materials have been published by Barrio Perez-Cenerai, (1977), Gutiérrez Rosales (1988), and Gasparoli (1990). Kiritsakis (1984a,b, 1998) has studied the effect of olive storage, processing systems, oil storage conditions and packaging materials on Greek olive oil quality. Several researchers have also done work on the influence of extraction methods on olive oil quality (Martinez et al, 1974, De Felice, 1979, Di Giovachino, 1994).

The objective of the present study was to evaluate the extent of degradation in the quality of some Greek virgin olive oils extracted by representative machinery types during storage. In order to investigate the possibility of improving the stability of the oil, an attempt was made to study the protective activity of the commercial plastic packaging material (polyethylene bottles) most commonly in use in the Greek market against autoxidation.

\section{EXPERIMENTAL PROCEDURES}

\subsection{Processing}

In this study the most representative processing systems used in Greece were tested. These are the Classic system of Theocharis with a Molacer of $14 \mathrm{in}$, the three phase centrifugals Alfa-Laval of Cosi type with D314 and Amenduni A/350 and the mixed type Rapanelli N/54 (Sinolea and Decanter). The oil obtained by the mixed system of Rapanelli (Sinolea and Decanter) was studied separately.

Olive fruits from the cultivar "Koroneiki" were collected and the entire mass about 4 tones was divided into four parts after mixing. These parts were not equal, since the quantity needed for a normal operation is different for each system. This procedure was repeated nine times.

For the classical system the following steps were carried out: i. Leaf removal from olive lots, ii. Washing, iii. Crushing by cylindrical triturators, iv. Grinding by round granite mill wheels, v. Kneading of the paste vi. Load formation with four paste-filled mats (filter disks) and one empty between two metal disks, vii. Pressing at 400 atm for $55 \mathrm{~min}$, and viii. Separation of the oil by means of an automated vertical discharge centrifuge.

For the three phase centrifugal decanters the following procedure was performed: The two first steps were the same as above, iii. Milling of drupes by a hammer crusher, iv. Kneading of the paste, v. Fluidification of the paste with $40 \%$ water and centrifugation, and vi. Separation of the oil by means of a manual vertical discharge centrifuge.

The conditions used in the different systems were as follows. The mean temperature recorded was $26^{\circ} \mathrm{C}$ for the Classic system, $27^{\circ} \mathrm{C}$ for the Rapanelli Sinolea system and $30^{\circ} \mathrm{C}$ for the three centrifugal systems of Alfa-Laval, Amenduni and Rapanelli Decanter. The mixing duration for the Classic and Mixed system was 45 min while for the other systems it was $30 \mathrm{~min}$.

\subsection{Olive oil analyses}

Olive oil (unfiltered) obtained from each system was initially analyzed for moisture, acidity, peroxide value, absorption in UV (extinction coefficients $\mathrm{K}_{232}$ and $\mathrm{K}_{270}$ ) and iron content (EC Commission Regulation 2568/91). Samples of the olive oil derived from the nine trials were combined together in $1 \mathrm{~L}$ plastic containers and stored at room temperature under different light conditions for eleven months. Three different light intensities were studied: a. Direct sunlight b. Diffused daylight and c. Darkness, one bottle for each case. The extend of oxidation of the olive oil during storage in plastic bottles was determined by measurement of the peroxide value and the extinction coefficients $K_{232}$ and $K_{270}$ once a month.

\section{RESULTS AND DISCUSSION}

\subsection{Initial quality of olive oil}

Results for the initial analyses (average of nine trials) of olive oil samples obtained from the different extraction systems are presented in Table I. One way of analysis of variance (ANOVA) has been applied to these. There are significant differences between the different systems in the characteristics of moisture, acidity, peroxide value (PV), the coefficient extinction $\mathrm{K}_{232}$ and the iron content. The moisture content and acidity in samples extracted with the Classic system were significantly higher than those extracted using the other systems. The moisture content for all samples was less than $0.6 \%$, while the acidity was no greater than $0.5 \%$. The initial PV for all the samples was less than $10 \mathrm{megO}_{2} / \mathrm{kg}$ and the mean value measured for the Classic system was significantly lower compared with the other systems. These peroxides may have been formed in the oil before the removal of the fruits from the tree. The iron content in samples extracted using the Classic system was significantly higher than that for the other systems due to contact with the metal surface of the equipment of the former case. Only the $\mathrm{K}_{270}$ values 
Table I

Means of initial quality parameters of olive oil extracted by the different systems (average of nine trials)

\begin{tabular}{lcccccc}
\hline Extraction system & $\begin{array}{c}\text { Moisture } \\
\%\end{array}$ & $\begin{array}{c}\text { Acidity } \\
\text { oleic acid\% }\end{array}$ & $\begin{array}{c}\text { Peroxide value } \\
\text { meql02 Kg }\end{array}$ & K232 & K270 & $\begin{array}{c}\mathrm{Fe} \\
\mathbf{m g} / \mathbf{K g}\end{array}$ \\
\hline CLASSIC & $0,5 \mathrm{~b}^{*}$ & $0,5 \mathrm{c}$ & $7,5 \mathrm{a}$ & $1,44 \mathrm{ab}$ & $0,2 \mathrm{a}$ & $4.11 \mathrm{~b}$ \\
ALFA LAVAL & $0,3 \mathrm{a}$ & $0,3 \mathrm{a}$ & $8,6 \mathrm{~b}$ & $1,56 \mathrm{~b}$ & $0,17 \mathrm{a}$ & $0,98 \mathrm{a}$ \\
AMENDUNI & $0,5 \mathrm{~b}$ & $0,4 \mathrm{~b}$ & $9,6 \mathrm{bc}$ & $1,52 \mathrm{~b}$ & $0,19 \mathrm{a}$ & $0,38 \mathrm{a}$ \\
RAPANELLI S & $0,2 \mathrm{a}$ & $0,4 \mathrm{~b}$ & $9,2 \mathrm{bc}$ & $1,44 \mathrm{ab}$ & $0,2 \mathrm{a}$ & $0,51 \mathrm{a}$ \\
RAPANELLI D & $0,2 \mathrm{a}$ & $0,4 \mathrm{~b}$ & $9,8 \mathrm{c}$ & $1,29 \mathrm{a}$ & $0,2 \mathrm{a}$ & $0,62 \mathrm{a}$ \\
\hline
\end{tabular}

*Values followed by the same letter vertically do not differ statistically at the $5 \%$ level

were found not to differ statistically among the different systems.

\subsection{Oxidation of olive oil stored in polyethylene bottles}

In order to estimate the extent of olive oil quality degradation with time, the peroxide value and the UV absorbance indices $\mathrm{K}_{270}$ and $\mathrm{K}_{232}$ of the oil stored in high-density polyethylene bottles were studied under three different light conditions: direct sunlight, diffused light and darkness during the 11 months
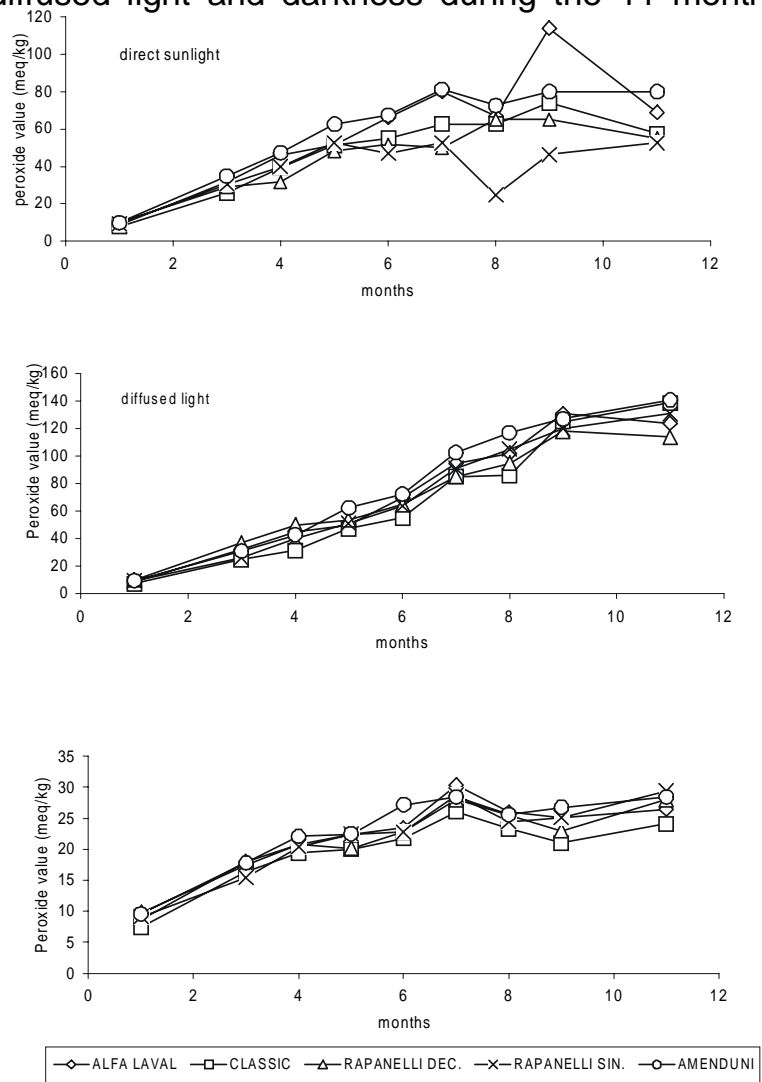

Figure 1

Influence of oil extraction systems and storage time on the peroxide value of olive oil stored in polyethylene bottles for eleven months under direct sunlight, diffused light and in darkness. storage. The evolution of the quality parameters for olive oil extracted using the different systems and stored under these different light conditions is shown in Figures 1, 2 and 3.

\subsection{Peroxide value (PV) evolution}

In samples of olive oil extracted using the different systems and stored under direct light a high increase in the peroxide value was observed during the first seven months of storage (Figure 1). Generally,
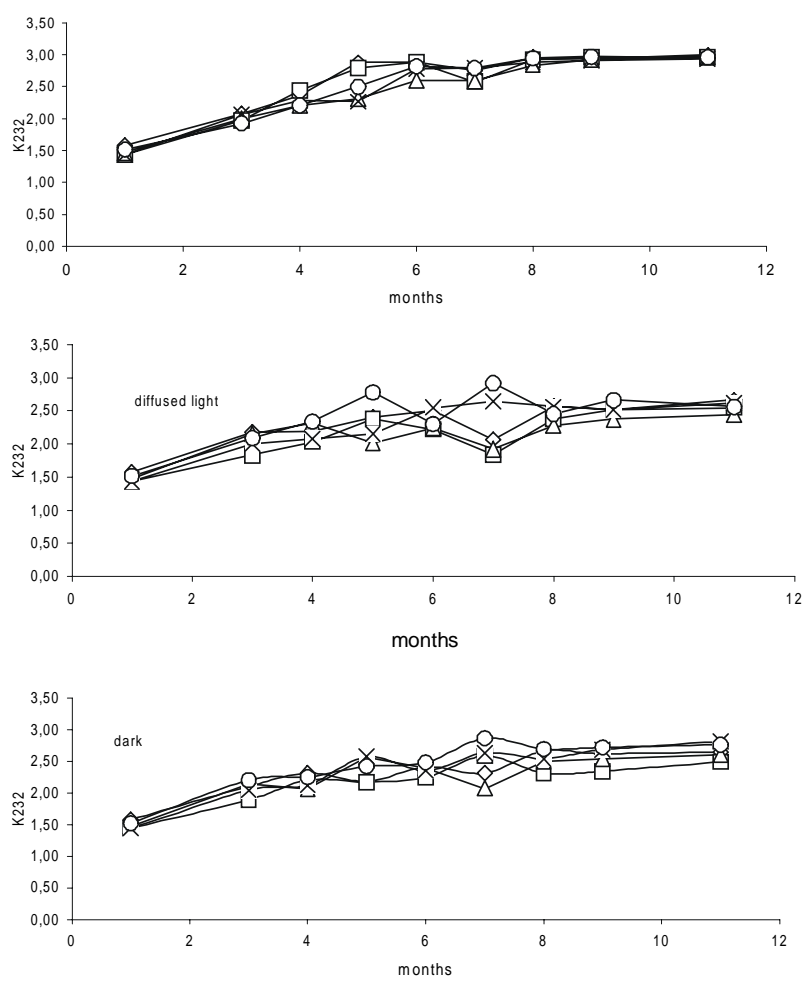

$\multimap \rightarrow$ ALFA LAVAL $\rightarrow \square-$ CLASSIC $\rightarrow-$ RAPANELLI DEC. $-x-$ RAPANELLI SIN. $-0-$ AMENDUNI

Figure 2

Influence of storage condition (direct sunlight, diffused light and darkness) on the $\mathrm{K}_{232}$ index of the olive oil extracted using different systems and stored in polyethylene bottles for eleven months. 

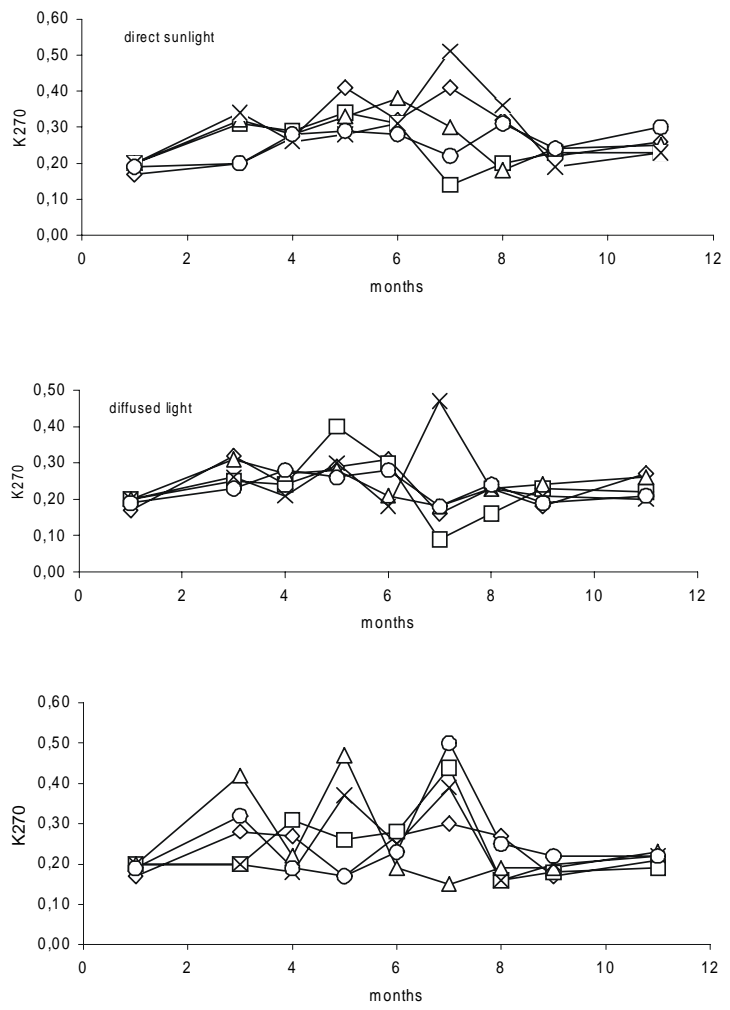

- - ALFA LAVAL - -CLASSIC $-\triangle-$ RAPANELLI DEC. $\rightarrow$-RAPANELLI SIN. -0 -AMENDUNI

Figure 3

Influence of storage condition (direct sunlight, diffused light and darkness) on the $\mathrm{K}_{270}$ index of the olive oil extracted by different systems and stored in polyethylene bottles for eleven months.

peroxide values followed a polynomial equation of the $Y=a x^{2}+b x+c$ type.

In diffused light, the increase in PV during storage followed a linear equation. In table II the correlation coefficients and regression equation of the peroxide values of oil extracted using the different systems and stored in diffused light are presented. The slope coefficients were high in all systems and the correlation coefficient was close to 1 . In samples of olive oil stored in darkness an increase in PV was observed in all the systems during the first seven

Table II

Correlation Coefficient and Regression Equation of the peroxide value in the different extraction systems for samples stored under diffused light

\begin{tabular}{lcc}
\hline \multicolumn{1}{c}{$\begin{array}{c}\text { Extraction } \\
\text { systems }\end{array}$} & $\begin{array}{c}\text { R2 (Correlation } \\
\text { Coefficient) }\end{array}$ & $\begin{array}{c}\text { Regression } \\
\text { equation }\end{array}$ \\
\hline CLASSIC & 0,9575 & $\mathrm{y}=14,159 \mathrm{x}-18,132$ \\
ALFA LAVAL & 0,9474 & $\mathrm{y}=13,235 \mathrm{x}-6,3077$ \\
RAPANELLI DEC. & 0,9576 & $\mathrm{y}=11,341 \mathrm{x}+1,7094$ \\
RAPANELLI SIN. & 0,9745 & $\mathrm{y}=13,582 \mathrm{x}-10,592$ \\
AMENDUNI & 0,9754 & $\mathrm{y}=14,526 \mathrm{x}-8,6983$ \\
\hline
\end{tabular}

months (Figure 1). After this period of time, a reduction occurred probably due to the break up of peroxides into secondary products. In all systems the $\mathrm{PV}$ followed an exponential equation $\mathrm{y}=\mathrm{a} \cdot \ln (\mathrm{x})+\mathrm{b}$ with a high $R^{2}$ value. The slope coefficient of $P V$ showed that the increase was highly significant in all types of systems during the storage time.

The peroxide value of oil samples extracted using the Classic system and stored in darkness did not exceed the limit of $20 \mathrm{meqO}_{2} / \mathrm{Kg}$ of oil until the fifth month of storage and values remained close to this during the remaining storage period. For the other light conditions, the content in peroxides passed the limit of $20 \mathrm{meq} \mathrm{O}_{2} / \mathrm{Kg}$ of oil and continued increasing.

The statistical analysis (Table III) showed that there were not significant differences in the values of PV among the systems for the samples stored under each of the light conditions.

The peroxide value for oil samples extracted using the Classic system was maintained at a low. This fact could be attributed to the higher

Table III

Means of quality parameters of olive oil extracted by the different systems (average of nine trials) and stored under different light conditions

\begin{tabular}{|c|c|c|c|}
\hline $\begin{array}{l}\text { Sunlight } \\
\text { Extraction } \\
\text { systems }\end{array}$ & $\begin{array}{l}\text { Peroxide value } \\
\text { meq102 } \mathrm{Kg}\end{array}$ & K232 & K270 \\
\hline CLASSIC & $48,7 a^{*}$ & $2.55 a$ & $0,25 \mathrm{a}$ \\
\hline ALFA LAVAL & $59,3 a$ & $2.60 \mathrm{a}$ & $0,29 a$ \\
\hline AMENDUNI & $59,5 a$ & $2,52 a$ & $0,26 \mathrm{a}$ \\
\hline RAPANELLI S. & $39,4 a$ & $2,48 a$ & $0,30 a$ \\
\hline RAPANELLI D. & $45 a$ & $2,43 a$ & $0,28 \mathrm{a}$ \\
\hline Standard Deviation & 21,3 & 0,48 & 0,07 \\
\hline $\begin{array}{l}\text { Diffused light } \\
\text { Extraction } \\
\text { systems }\end{array}$ & $\begin{array}{l}\text { Peroxide value } \\
\text { meq102 Kg }\end{array}$ & K232 & K270 \\
\hline CLASSIC & $66,8 a$ & $2,13 a$ & $0,23 a$ \\
\hline ALFA LAVAL & $73,1 \mathrm{a}$ & $2,29 a$ & $0,24 a$ \\
\hline AMENDUNI & $78,4 a$ & $2,40 a$ & $0,23 a$ \\
\hline RAPANELLI S. & $70,9 a$ & $2,28 a$ & $0,25 a$ \\
\hline RAPANELLI D. & $69,8 a$ & $2,13 a$ & $0,24 a$ \\
\hline Standard Deviation & 40,7 & 0,35 & 0,06 \\
\hline $\begin{array}{c}\text { Dark } \\
\text { Extraction } \\
\text { systems }\end{array}$ & $\begin{array}{l}\text { Peroxide value } \\
\text { meq102 Kg }\end{array}$ & K232 & K270 \\
\hline CLASSIC & $19,9 a$ & $2,18 \mathrm{a}$ & $0,25 \mathrm{a}$ \\
\hline ALFA LAVAL & $22,4 a$ & $2,31 \mathrm{a}$ & $0,23 a$ \\
\hline AMENDUNI & $23,2 a$ & $2,43 a$ & $0,25 \mathrm{a}$ \\
\hline RAPANELLI S. & $22,0 a$ & $2,35 a$ & $0,24 a$ \\
\hline RAPANELLI D. & $21,7 a$ & $2,25 a$ & $0,25 a$ \\
\hline Standard Deviation & 5,8 & 0,36 & 0,08 \\
\hline
\end{tabular}

*Values followed by the same letter vertically do not differ statistically at the $5 \%$ level 
Table IV

Means of quality parameters of olive oil extracted by the different systems and stored under different light conditions

\section{Peroxide value (meq02/kg)}

\begin{tabular}{lcccc}
\hline \multicolumn{1}{c}{ Light Conditions } & CLASSIC & ALFA-LAVAL & AMENDUNI & RAPANELLI S. \\
\hline Direct sunlight & $48,7 \mathrm{~b}^{*}$ & $59,3 \mathrm{~b}$ & $59,5 \mathrm{~b}$ & $39,4 \mathrm{a}$ \\
Diffused light & $66,8 \mathrm{~b}$ & $73,1 \mathrm{~b}$ & $78,4 \mathrm{~b}$ & $70,9 \mathrm{~b}$ \\
Dark & $19.9 \mathrm{a}$ & $22,4 \mathrm{a}$ & $23,2 \mathrm{a}$ & $69,8 \mathrm{~b}$ \\
\hline
\end{tabular}

K232

\begin{tabular}{|c|c|c|c|c|c|}
\hline Light Conditions & CLASSIC & ALFA-LAVAL & AMENDUNI & RAPANELLI S. & RAPANELLI D. \\
\hline Direct sunlight & $2,55 b$ & $2,60 \mathrm{a}$ & $2,52 a$ & $2,48 a$ & $2,43 a$ \\
\hline Diffused light & $2,13 a$ & $2,29 a$ & $2,40 a$ & $2,28 a$ & $2,13 a$ \\
\hline Dark & $2,18 a b$ & $2,31 \mathrm{a}$ & $2,43 a$ & $2,35 a$ & $2,25 a$ \\
\hline
\end{tabular}

K270

\begin{tabular}{|c|c|c|c|c|c|}
\hline Light Conditions & CLASSIC & ALFA-LAVAL & AMENDUNI & RAPANELLI S. & RAPANELLI D. \\
\hline Direct sunlight & $0,25 a$ & $0,29 a$ & $0,26 a$ & $0,30 a$ & $0,28 a$ \\
\hline Diffused light & $0,23 a$ & $0.24 a$ & $0,23 a$ & $0,25 a$ & $0,24 a$ \\
\hline Dark & $0,25 a$ & $0.23 a$ & $0,25 a$ & $0,24 a$ & $0,25 a$ \\
\hline
\end{tabular}

polyphenolic content (Vekiari, 2001) of this system, although the content of $\mathrm{Fe}$, acidity and moisture was high. These parameters are known as prooxidant factors and act as free radical generators and promoters of hydrolytic autoxidation (Boskou, 1996).

Significant differences were observed in the peroxide value of the samples stored under the different light conditions (Table IV). The lowest values of $\sim 21 \mathrm{meqO}_{2} / \mathrm{Kg}$ were measured for the samples stored in darkness while high peroxide values were generally measured when samples were stored under direct and diffused light. This maybe an indication, that beyond the systems and the effect of light, another external factor like the packaging material, the precipitated substances and the repeated opening of the same bottle acted additionally and caused this increase.

Gutiérrez González-Quijano and Olías Jiménez (1970) compared samples stored in tin plates, glass, PVC and polyethylene bottles, in darkness and light at $28-30^{\circ} \mathrm{C}$, and found that the spoilage time, as indicated by an increase of PV above acceptable limits, was higher for polyethylene when compared with the other packaging materials. Unal (1981), comparing the effect of light on the deterioration rate of samples of virgin olive oil stored in cans, colorless glass bottles, and PVC bottles, found higher rates of deterioration in samples stored in light, and higher PV in samples stored in PVC bottles. The influence of polyethylene as a packaging material on the PV may not only be attributable to the diluted oxygen but also to the oxygen found in the upper vacant part of the plastic bottle. The transparency of the walls may be another reason for this phenomenon. Peroxides formed during contact of the oil with the walls may move into the oil and catalyze the oxidation reaction (Gonzáles-Quijano, 1970). Another factor which may influence the oil quality is the lack of filtration of the oil. It is known that resins and other substances undiluted in petroleum ether that pass into the oil during the extraction process may promote the beginning of fermentation during storage (Petruccioli, 1975).

\subsection{Coefficient extinction $\mathrm{K}_{232}$ and $\mathrm{K}_{270}$}

The values of $\mathrm{K}_{232}$ in samples stored in darkness showed an increase during the first seven months (Figure 2). The increase followed a polynomial equation of the type $\mathrm{Y}=a \mathrm{x}^{2}+\mathrm{bx}+\mathrm{c}$ with a high correlation coefficient $R^{2}$. The slope coefficients for different systems do not differ significantly. The $\mathrm{K}_{232}$ index followed the same type of equation when the samples were exposed to direct and diffused light. The $\mathrm{K}_{232}$ values did not exceed the limit value of 2,5 in the dark and diffused light in samples obtained using all systems. The statistical analysis of the data (ANOVA) showed that there were no significant differences in the values of $\mathrm{K}_{232}$ among the extraction systems and among the different light conditions 
(Table III and IV). The only differentiation was that there were significant differences among the light intensities for the Classic system.

The $K_{270}$ values did not exceed the value of 0,30 for the edible virgin olive oil using all systems under the three light conditions (Figure 3). Generally, the values of $K_{270}$ were close to 0.2 at the beginning of the experiment, with the limit being 0.20 . Samples stored in darkness kept better probably due to the fact that the presence of chlorophyll in the oil acts as antioxidant in the dark (Kiritsakis, 1984). The statistical analysis showed that there were no significant differences among the systems during the storage period of 11 months and among the three different light conditions (Table III and IV).

The $K_{270}$ values for the oil obtained using the Sinolea extraction system were lower compared with those using the Decanter system. This could be attributed to the different procedure followed for their extraction: The Rapanelli Sinolea procedure does not require water for the malaxation step, while the Rapanelli Decanter demands water, leading to a possible decrease in natural antioxidants and hence a lower resistance to autoxidation.

\section{CONCLUSIONS}

Olive oil extracted using the different extraction systems did not show statistical differences for the different systems and the quality parameters.

From the results it was concluded that oxidation proceeded at the lowest rate in darkness and the highest in direct and diffused light. Generally, samples stored in the dark showed slower deterioration while those stored under the other light conditions were oxidized very quickly. Therefore, the conditions used for storing olive oil in polyethylene bottles must be reassessed in order to maintain better its quality. Even a small exposure to light accelerates peroxide formation in the oils. Generally, storage under direct sunlight or diffused light promotes the beginning of the oxidation phenomenon, accelerates it and then retards it because of peroxide break up. An opaque packaging that could protect the oil from exposure to light or the storage of oil in darkness if it is to be stored for a long time could provide a solution to this problem.

Polyethylene as a transparent packing material was not a good packaging means for olive oil preservation. Obviously, the length of storage time in the container as well as the presence of air within the container both affected the quality of the product. So, beyond the best price/value relationship, the protection the packaging material offers to the product plays an important role to the final decision.

\section{BIBLIOGRAPHY}

Barrio Pérez-Cenerai, A., Gutiérrez Rosales, F. y Gutiérrez González-Quijano, R. (1977). Conservación del aceite de oliva en depósitos de poliester-fibra de vidrio. Grasas Y Aceites, 28 (1), 5-9.

Boskou, D. (1996). In; OLIVE OIL: Chemistry and Technology.Ed. D. Boskou, AOCS Press, Champaign, Illinois, $161 \mathrm{pp}$.

Di-Giovachino, L., Solinas, M., Miccoli, M. (1994). Effect of extraction systems on the quality of virgin olive oil. $J$. Am. Oil Chem. Soc. 71 (11), 1189-1194.

De Felice, M., Gomes, T. and Catalano, M. (1979). Centrifugazione delle paste. Risultati di ricerche trienali. Riv. Ital. Sostanze Grasse, 56, 361-369.

Gasparoli, A. and Fedeli, E. (1990). Indagine preliminare sulla valutazione della conservabilita di oli extra vergini confezionati.. Riv. Ital. Sostanze Grasse, LXVII, 81-87.

Gutiérrez Gonzalez-Quijano, R. y Olías Jiménez, J.M. (1970). Sobre el envasado del aceite de oliva en recipientes de uso comercial. II. La conservación en recipientes de vidrio, hojalata, polietileno y cloruro de polivinilo. Evolución del índice de peróxidos. Grasas y Aceites, 21 (4), 217-225.

Gutiérrez Rosales, F., Gómez Herrera, C. y Gutiérrez González-Quijano (1988). Estudio de la cinética de evolución de los índices de calidad del aceite de oliva virgen durante su conservacion en envases comerciales. Grasas y Aceites, 39 (4-5), 245-253.

Kiritsakis, A. and Dugan, LR. (1984). Effect of selected storage conditions and packaging materials on olive oil quality. J. Am. Oil Chem. Soc. 61 (12), 1868-1870.

Kiritsakis, A., Koutsaftakis, A. and Mikros, L. (1984). The effect of processing systems pieralisi, Hiller and Rapanelli (Sinolea-Decanter) on olive oil quality. Grasas y Aceites, 36 (3), 165-170.

Kiritsakis, A. (1988). In: Olive Oil. Ed. 1st, Ed. A. Kiritsakis, The Agro-Association Union S.A. Publishers, 111-118.

Kiritsakis, A., Nanos, GD, Polymenopoulos, Z., Thomai, T. and Sfakiotakis, EM. (1998). Effect of fruit storage conditions on olive oil quality. J. Am. Oil Chem. Soc., 75 (6), 721-724.

Leo, D.A. and Clayton, W.L. (1983). Effect of packaging on oil product quality. J. Am. Oil Chem. Soc. 60 (2), 253-255.

Martínez Suárez, J.M., Muñoz Aranda, E., Alba Mendoza, J. y Lanzón Rey, A. (1974). Elaboración del aceite de oliva por cenrifugación en continuo. Grasas y Aceites, 25 (3), 149-158.

Petruccioli, G. (1975). Oil extraction In: Olive oil Technology. Rome, FAO, 32-34.

Stavroulakis, G. and Petrakis, C. (1998). Production and quality of ecological olive oil. Proceedings of $18^{\text {th }}$ Scientific Meeting of Greek Company of the Vegetable Science (in press).

Unal, K. (1981). Change in quality of virgin olive oil during storage for 24 months. Food Science and Technology Abstracts, 8N, $393-398$.

Vekiari, S. (2001). Olive oil polyphenols and their significance in its quality. Chemica Chronica, 63 (2), 45-48.

The Commission of the European Communities, Regulation No. 2568 (1991). On the Characteristics of Olive Oil and Olive Residue Oil and the Relevant Methods of Analysis. Official Journal of the European Communities. No. L248. 